Scripta Materialia: Viewpoint Set

\title{
Importance of high power factor in thermoelectric materials for power generation application: a perspective
}

\author{
Weishu Liu ${ }^{\dagger}$, Hee Seok Kim†, Qing Jie, and Zhifeng Ren* \\ Department of Physics and TcSUH, University of Houston, Houston, TX 77204, USA \\ * To whom correspondence should be addressed: zren@uh.edu; ${ }^{\dagger}$ Equal contribution
}

\begin{abstract}
:
The figure of merit $(Z T)$ has been used for more than half a century to guide the research of thermoelectric materials. In this perspective viewpoint, we emphasize that the power factor (PF) is more important than the thermal conductivity for thermoelectric power generation for a given $Z T$. We also propose the newly defined engineering parameters $(Z T)_{\text {eng }} \&(P F)_{\text {eng }}$ are the more practical indicators to show the temperature dependent efficiency \& output power, as compared with conventional $Z T \& P F$.
\end{abstract}

Keywords: Thermoelectric, Power factor, Figure of merit, $(P F)_{\text {eng, }}(Z T)_{\text {eng }}$

To whom correspondence should be addressed: zren@uh.edu 
Thermoelectric energy conversion has the advantage to harvest widely distributed waste heat, and is also proved as an alternative route to convert solar energy into electric power economically. Thermoelectric phenomena were discovered in metals in 1821, however, it did not attract enough scientific interests for energy conversion until the 1950s due to the low conversion efficiency [1-4]. After the pioneering efforts, semiconductors such as $\mathrm{Bi}_{2} \mathrm{Te}_{3}, \mathrm{PbTe}$, and $\mathrm{SiGe}$ based thermoelectric materials were developed as good thermoelectric materials due to the reduced thermal conductivity by the alloying effect. However, the dimensionless thermoelectric figure of merit $(Z T)$ of these materials has been limited to the benchmark value of $Z T=1$ for a long time. Here, $Z T$ is defined as $Z T=\left(S^{2} \sigma / \kappa\right) T$, where $S, \sigma, \kappa$, and $T$ are the Seebeck coefficient, electrical conductivity, thermal conductivity, and absolute temperature, respectively. Although the benefits of the solid state thermoelectric devices are notable, the ineffective energy conversion $(<5 \%)$ resulted in only niche market, such as power supply for the space exploring mission and portable refrigerator. After the huge declining in research during 1970s-1990s, thermoelectrics get revived in 1990s under the influence of fossil fuel energy crisis. The main activity in the 1990s was to explore the next generation of thermoelectric materials through two approaches: new materials with low thermal conductivity, and low-dimensional systems for improved power factor $(P F)$ [5-7]. After 2000s, these two approaches started to merge [8]. The low dimensional structures are artificially introduced into the host matrix to form the nanostructured materials, or nanocomposite, which significantly reduces the lattice thermal conductivity resulting in enhanced $Z T$ values [9-11]. One of the remarkable examples is the ptype $\mathrm{Bi}_{0.4} \mathrm{Sb}_{1.6} \mathrm{Te}_{3}$ material, where $40 \%$ enhancement in $Z T$ value from 1.0 to 1.4 was observed by applying a ball milling and hot pressing process to an ingot [11]. The new $\mathrm{Bi}_{0.4} \mathrm{Sb}_{1.6} \mathrm{Te}_{3}$ nanocomposite characterized with the multi-size scale phonon scattering centers, includes fine grains of $50 \mathrm{~nm}-2 \mu \mathrm{m}$, nano inclusions of $5-20 \mathrm{~nm}$, and atomic defects less than $5 \mathrm{~nm}$, which successfully reduced the lattice thermal conductivity [12].

Pursuing high $Z T$ has been the focus of the entire thermoelectric community by applying various phonon engineering via nano approaches to reduce the thermal conductivity [13-25], or by exploring new compounds with intrinsically low thermal conductivity, such as compounds having a complex crystalline structure, local rattlers, liquid like sub-lattice, and highly distorted lattice [26-37]. However, we recently realized that efficiency controlled by $Z T$ is not the only concern for practical applications. In contrast, the output power is in fact equivalently as 
important as the efficiency, or more important when the heat source is unlimited (such as solar heat), or heat source is free (such as waste heat from automobiles, steel industry, etc.) [38]. In this perspective, we will discuss the importance of high $P F$ in thermoelectric materials for a power generation application, and also suggest that seeking high $P F$ for the high output power has an advantage in terms of thermo-mechanical reliability for a given efficiency.

Theoretically, the efficiency $\eta$ of thermoelectric power generation is determined by the figure of merit $Z=\mathrm{S}^{2} \sigma / \kappa$ while the output power density $\omega$ is related to power factor $P F=S^{2} \sigma$ as following,

$$
\begin{aligned}
\eta_{\max } & =\frac{T_{h}-T_{c}}{T_{h}}\left(\frac{\sqrt{1+Z\left(T_{h}+T_{c}\right) / 2}-1}{\sqrt{1+Z\left(T_{h}+T_{c}\right) / 2}+T_{c} / T_{h}}\right), \\
\omega_{\max } & =\frac{1}{4} \frac{\left(T_{h}-T_{c}\right)^{2}}{L} P F,
\end{aligned}
$$

where $T_{h}, T_{c}$, and $L$ are the hot side temperature, cold side temperature, thermoelectric leg length. In Eq. (2), there are three parts: temperature difference $\left(T_{h}-T_{c}\right)$, temperature gradient $\left(T_{h}-T_{c}\right) / L$, and power factor $P F$. The temperature difference $\left(T_{h}-T_{c}\right)$ and temperature gradient $\left(T_{h}-T_{c}\right) / L$ are the working boundary conditions and the power factor $S^{2} \sigma$ is the material parameter. For given boundary conditions, $\omega$ is only governed by $P F$. It is noted that Eq. (1-2) are derived from constant transport property model, in which all the thermoelectric parameters $S, \sigma$, and $\kappa$ are assumed to be temperature independent. Practically, most materials show strong temperature dependent thermoelectric transport properties. The $Z T$ is commonly used as an index to evaluate the thermoelectric performance. We recently pointed out that the efficiency predicted by Eq. (1) based on prevailing averaging methods is often misleading and gives rise to a very large overestimation in some situations [39][40]. One of the reasons is the measured $Z T$ represents a local characteristic at a given temperature, i.e., $T_{h}=T+\delta$ and $T_{c}=T-\delta$ where $\delta$ is an infinitely small temperature difference. In other words, Eq. (1) is only effective in a small temperature range due to heavy temperature dependent thermoelectric properties of materials. To account for the temperature dependence of $S, \sigma$, and $\kappa$ for more accurate efficiency and output power predictions, a numerical calculation based on the energy balance equation for one-dimensional heat flow is required [41]. 


$$
\frac{d}{d x}\left(\kappa(x) \frac{d T(x)}{d x}\right)+J^{2} \rho(x)-J T(x) \frac{d S(x)}{d x}=0,
$$

where $J$ is the current density. These equations are solved iteratively to match the temperature boundary conditions at a given current density. In order to solve the nonlinear differential equation, a finite difference method is used. A TE leg is segmented along the heat flow direction for 1-D analysis, and approximated temperature and TE properties at each segment elements are calculated, which yields a linear relation between infinitesimal elements as [42],

$$
\frac{\kappa_{i+1}-\kappa_{i-1}}{2 \delta x} \frac{T_{i+1}-T_{i-1}}{2 \delta x}+\kappa_{i} \frac{T_{i+1}-2 T_{i}+T_{i-1}}{(\delta x)^{2}}+J^{2} \rho_{i}-J T_{i} \frac{S_{i+1}-S_{i-1}}{2 \delta x}=0,
$$

where, $i=1,2,3, \ldots, \mathrm{n}-1, n$ is the number of segments, and $\delta x$ is length of each segment. By iterating until the temperature distribution $T_{i}$ and electric current $I$ are converged, the output power, input heat, and efficiency are obtained as,

$$
\begin{aligned}
& P_{\text {out }}=I^{2} R_{L}, \\
& Q_{h}=I T_{1} S_{1}+A \kappa_{1} \frac{T_{1}-T_{2}}{\delta x}-\frac{1}{2} \rho_{1} \frac{\delta x}{A}-\frac{1}{2} I T_{1}\left(S_{1}-S_{2}\right), \\
& \eta=\frac{P_{\text {out }}}{Q_{h}},
\end{aligned}
$$

where $R_{L}$ is the load resistance. In order to address the importance of $P F$, we compared two reported materials, $\mathrm{PbSe}$ [43] and $\mathrm{Hf}_{0.25} \mathrm{Zr}_{0.75} \mathrm{NiSn}$ [44], as shown in Fig. 1. Both materials have similar cubic crystalline structure. However, the difference on their thermoelectric properties is obvious, as shown in Fig.1 (a-e). First, the electrical conductivity and thermal conductivity of $\mathrm{PbSe}$ are lower than those of $\mathrm{Hf}_{0.25} \mathrm{Zr}_{0.75} \mathrm{NiSn}$. It is because of the intrinsic resonant bonding of $\mathrm{PbSe}$ as suggested recently [45]. Although PbSe has lower power factor $\left(P F_{\max }=21 \mu \mathrm{W} \mathrm{cm}^{-1} \mathrm{~K}^{-}\right.$ $\left.{ }^{2}\right)$, it has higher $Z T\left(Z T_{\max }=1.3\right)$ due to much lower thermal conductivity $\left(\kappa_{\min }=0.89 \mathrm{~W} \mathrm{~m}^{-1} \mathrm{~K}^{-1}\right)$ as compared with $\mathrm{Hf}_{0.25} \mathrm{Zr}_{0.75} \mathrm{NiSn}\left(P F_{\max }=52 \mu \mathrm{W} \mathrm{cm}{ }^{-1} \mathrm{~K}^{-2}, Z T_{\max }=1, \kappa_{\min }=4 \mathrm{~W} \mathrm{~m}^{-1} \mathrm{~K}^{-1}\right)$. Second, $\mathrm{PbSe}$ has stronger temperature dependence of electrical conductivity and Seebeck

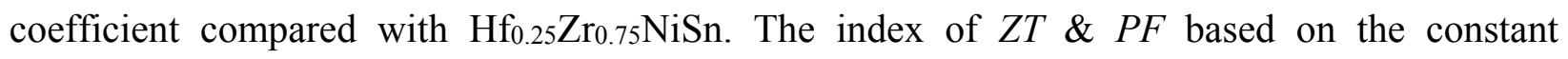
properties model becomes less valid to evaluate the leg efficiency and output power for the materials with strong temperature-dependent $S, \sigma$, and $\kappa$.In contract, the numerical simulation was needed to calculate the leg efficiency and output power. At a given hot side temperature $\left(T_{h}\right.$ $\left.=550^{\circ} \mathrm{C}\right)$ and cold side temperatures $\left(T_{c}=50^{\circ} \mathrm{C}\right)$ with a leg length $(L=2 \mathrm{~mm})$ as the boundary 
conditions, the calculation shows that PbSe has a theoretical leg efficiency of $\sim 11 \%$, which is slightly higher than $\sim 10 \%$ for $\mathrm{Hf}_{0.25} \mathrm{Zr}_{0 .}{ }_{5} \mathrm{NiSn}$. If the efficiency is the only concern, $\mathrm{PbSe}$ is definitely better than $\mathrm{Hf}_{0.25 \mathrm{Zr}} 0.75 \mathrm{NiSn}$. However, under the same boundary conditions $\left(T_{c}=50{ }^{\circ} \mathrm{C}\right.$, $\left.T_{h}=550{ }^{\circ} \mathrm{C}, L=2 \mathrm{~mm}\right)$, the $\mathrm{Hf}_{0.25} \mathrm{Zr}_{0.75} \mathrm{NiSn}$ leg has much higher output power $\left(\omega=14.4 \mathrm{~W} \mathrm{~cm}^{-2}\right)$ than that of the PbSe leg $\left(\sim 5.4 \mathrm{~W} \mathrm{~cm}^{-2}\right)$, as shown in Fig. 1(f). If we consider the leg length as the independent design parameter, a shorter PbSe leg could generate comparable power to the $\mathrm{Hf}_{0.25} \mathrm{Zr}_{0.75} \mathrm{NiSn}$ leg with $L=2 \mathrm{~mm}$. In order to match the power generated by $L=2 \mathrm{~mm}$ $\mathrm{Hf}_{0.25} \mathrm{Zr}_{0.75} \mathrm{NiSn}$ leg, the PbSe leg has to be shorten to $\sim 0.93 \mathrm{~mm}$ (inset of Fig. 1(f)).However, the shorter leg leads to a much larger thermo-mechanical reliability problem due to increased temperature gradient across the leg, which needs more attentions.

The mechanical and functional failures due to thermal stress have been widely known in the microelectronic and photonic component [46]. The shear stress generated at the interface between the TE leg and the metal electrode is proportional to $1 / \mathrm{L}$ due to their coefficient of thermal expansion (CTE) mismatch (local stress) and the difference of thermal expansion at hot and cold side assembly (global stress) [47]. Clin et al. [48] has done the finite element modeling by ANSYS for the stress distribution in $\mathrm{a} \mathrm{Bi}_{2} \mathrm{Te}_{3}$ module which is subjected to a temperature difference of $100{ }^{\circ} \mathrm{C}$ while keeping unconstrained surface, as shown in Fig. 2(a). It is found that the temperature difference deforms the module with a relative displacement of $2 \mu \mathrm{m}$ from the center of the substrate to the corner. They also suggested that the module with surface constrained by ceramic substrate develop higher stress at the bonding interface for a given boundary temperature. Schock et al. [49] reported similar simulation results about the stress and deformation generated by the temperature difference in a Skutterudite module under a larger temperature difference of $T_{h}=450{ }^{\circ} \mathrm{C}$ and $T_{c}=30{ }^{\circ} \mathrm{C}$ over a leg with a dimension of $3 \times 3 \times 7 \mathrm{~mm}^{3}$. It is found that the stresses caused by the temperature difference result in a mechanical failure at thermoelectric legs. Additionally, some of the plastic deformation was predicated after thermal cycles at the hot side. In the real device assembly, a metalized contact layer needs to be placed on the thermoelectric legs before it is joined with electrodes by solder. The thermal stresses not only cause the deformation of the thermoelectric and soldering materials, but also result in the mechanical failure at the contact interface between the metallization layer and the thermoelectric materials. Although the CTE mismatch between metallization layer and the thermoelectric materials can be minimized, it is still challenge to achieve good bonding and low contact 
resistivity simultaneously [50]. However, in some cases, the bonding strength has to be slightly sacrificed for the low contact resistance. As an example, in an n-type $\mathrm{Bi}_{2} \mathrm{Te}_{2.7 \mathrm{Se}} 0.3$ leg [51], the bonding strength of $\mathrm{Ni} / \mathrm{Bi}_{2} \mathrm{Te}_{2.7} \mathrm{Se}_{3.3}$ reached $20 \mathrm{MPa}$ by direct hot pressing at $500{ }^{\circ} \mathrm{C}$, while its contact resistance is extremely high as $200 \mu \Omega \mathrm{cm}^{2}$. A solution was to add a barrier layer and reduce hot pressing temperature from $500{ }^{\circ} \mathrm{C}$ to $425{ }^{\circ} \mathrm{C}$ to achieve a lower contact resistance below $1 \mu \Omega \mathrm{cm}^{2}$. However, the bonding strength is also reduced from 20MPa to $16 \mathrm{MPa}$. Fig. 2 (b) is a theoretical calculation of the shear stress between metal electrode and BiSbTe leg as a function of the leg length [52]. It is clearly shown that a higher stress is developed from a shorter leg at the bonding interface. Under the boundary temperatures of $T_{h}=200{ }^{\circ} \mathrm{C}$ and $T_{c}=25{ }^{\circ} \mathrm{C}$, the shear stress is $30 \mathrm{MPa}$ for a leg with $1.8 \mathrm{~mm}$ width and $1.0 \mathrm{~mm}$ length, which is comparable to or higher than the bonding strength between the metalized contact layer and the thermoelectric materials (10 MPa for Ni by sputtering or electrochemical deposition, and $30 \mathrm{MPa}$ for Ni by hot pressing). Fig. 3 (a-b) compares the contact interface of a $\mathrm{Bi}_{2} \mathrm{Te}_{3}$ based module after thermal cycles, in which one side is fixed at ambient temperature of $23{ }^{\circ} \mathrm{C}$ while the other side is heated up to $146{ }^{\circ} \mathrm{C}$ and then cooled down to $-20{ }^{\circ} \mathrm{C}$ [53]. Cracks are clearly shown at the contact interface of the module after thermal cycles, which also causes an increased internal electrical resistance of the module. Moreover, a shorter leg leads to a higher impact of contact resistance associated with the electrical resistance of a thermoelectric material, which degrades output power generation. In addition, ashorter leg requires more efforts on device assembly, which requires stronger bonding strength.

Unlike the negative effect of lowering $\kappa$ on thermo-mechanical stability, seeking higher $P F$ for both high efficiency and output power will not influence the bonding structure. Considering the equivalent importance of the efficiency and output power, we emphasize on using the dual-index to evaluate the thermoelectric performance of materials: $\eta$ and $\omega . Z T$ and $P F$ are considered as material parameters of $\eta$ and $\omega$, respectively. It is noted that Eq. (1) is based the constant property model without considering Thomson effect. After considering the Thomson effect, Eqs. (1-2) are rewritten into a general form [40],

$$
\begin{aligned}
& \eta_{\max }=\eta_{c} \frac{\sqrt{1+(Z T)_{e n g} \alpha_{1} / \eta_{c}}-1}{\alpha_{0} \sqrt{1+(Z T)_{e n g} \alpha_{1} / \eta_{c}}+\alpha_{2}}, \\
& \omega_{\max }=\frac{1}{4} \frac{\left(T_{h}-T_{c}\right)}{L}(P F)_{e n g},
\end{aligned}
$$




$$
\begin{gathered}
\alpha_{i}=\frac{S_{h}\left(T_{h}-T_{h}\right)}{\int_{T_{h}}^{T_{h}} S(T) d T}-\frac{\int_{T_{h}}^{T_{h}} \tau(T) d T}{\int_{T_{h}}^{T_{h}} S(T) d T} W_{T} \eta_{c}-i W_{J} \eta_{c} \\
W_{T}=\frac{\int_{T_{c}}^{T_{h}} \int_{T}^{T_{h}} \tau(T) d T d T}{\Delta T \int_{T_{c}}^{T_{h}} \tau(T) d T}, \\
W_{J}=\frac{\int_{T_{c}}^{T_{h}} \int_{T}^{T_{h}} \rho(T) d T d T}{\Delta T \int_{T_{c}}^{T_{h}} \rho(T) d T}, \\
(Z T)_{\text {eng }}=\frac{(P F)_{\text {eng }}}{\int_{T_{c}}^{T_{h}} \kappa(T) d T}\left(T_{h}-T_{c}\right), \\
(P F)_{\text {eng }}=\frac{\left(\int_{T_{c}}^{T_{h}} S(T) d T\right)^{2}}{\int_{T_{c}}^{T_{h}} \rho(T) d T},
\end{gathered}
$$

where $(Z T)_{\text {eng, }}(P F)_{\text {eng, }} \tau, S_{h}, \eta_{c}, W_{T}$, and $W_{J}$ are the engineering figure of merit, engineering power factor, Thomson coefficient, Seebeck coefficient at hot side, Carnot efficiency, weight factor of Thomson heat, and weight factor of Joule heat, respectively. (ZT)eng and (PF) eng are the newly defined engineering indices for a practical evaluation of thermoelectric materials [40]. When the constant property model without Thomson effect is considered, i.e., $W_{J}=1 / 2$ and $\tau=0$, $\alpha_{i}\left(i=0,1\right.$, and 2) becomes $\alpha_{0}=1, \alpha_{1}=\left(T_{h}+T_{c}\right) /\left(2 T_{h}\right)$, and $\alpha_{2}=T_{c} / T_{h}$, respectively, $(Z T)_{e n g}=$ $Z\left(T_{h}-T_{c}\right)$ and $(P F)_{e n g}=P F\left(T_{h}-T_{c}\right)$, so Eq. (8) is exactly reduced to Eq. (1). By using Eqs. (13-14) based on $(Z T)_{e n g}$ and $(P F)_{e n g}$, we can predict efficiency and output power more accurately as compared with those by Eqs. (1-2). Fig. 4 is an example for the efficiency calculation of $\mathrm{In}_{4} \mathrm{Se}_{3}$ by using Eq. (1) and Eq. (8) as compared with the numerical calculation, which shows a very good agreement between the numerical calculation with our newly derived relationship of efficiency and (ZT) eng [40].

$(Z T)_{e n g}$ and $(P F)_{e n g}$ are accumulative result over whole temperature range from $T_{c}$ to $T_{h}$, while $Z T$ and $P F$ only indicate the local characteristics at a given $T$. (ZT)eng and $(P F)_{\text {eng }}$, therefore, better represent the power generation performance of the thermoelectric leg under a large temperature difference. Fig. 5 shows thermoelectric performance of the selected n-type materials, 
including $\mathrm{Bi}_{2} \mathrm{Te}_{2.7} \mathrm{Se}_{0.3}$ [54], $\mathrm{AgPb}_{\mathrm{m}} \mathrm{SbTe}_{\mathrm{m}+2}$ [55], $\mathrm{Mg}_{2} \mathrm{Sn}_{0.75} \mathrm{Ge}_{0.25}$ [38], $\mathrm{Ba}_{x} \mathrm{La}_{\mathrm{y}} \mathrm{Yb}_{\mathrm{z}} \mathrm{Co}_{4} \mathrm{Sb}_{12}$ [54], $\mathrm{PbSe}$ [43], $\mathrm{Hf}_{0.25} \mathrm{Zr}_{0.75} \mathrm{NiSn}$ [44], and $\mathrm{Si}_{0.8} \mathrm{Ge}_{0.2} \mathrm{P}_{0.02}$ [56]. Fig. 5(a, b) is the conventional $P F$ and $Z T$. Among these selected materials, $\mathrm{Bi}_{2} \mathrm{Te}_{2.7} \mathrm{Se}_{3}, \mathrm{Mg}_{2} \mathrm{Sn}_{0.75} \mathrm{Ge}_{0.25}$, and $\mathrm{Ba}_{x} \mathrm{Lay}_{y} \mathrm{Yb}_{z} \mathrm{Co}_{4} \mathrm{Sb}_{12}$ show a notably higher conventional $P F$, which also result in higher $(P F)_{\text {eng }}$ (Fig. 5(c)) and hence higher output power for a given temperature gradient $\left(\mathrm{T}_{\mathrm{h}}-\mathrm{T}_{\mathrm{c}}\right) / \mathrm{L}=100{ }^{\circ} \mathrm{C} / \mathrm{mm}$ (Fig. 5(e). Another interesting comparison is between $\mathrm{AgPb}_{\mathrm{m}} \mathrm{SbTe}_{\mathrm{m}+2}$ and $\mathrm{Mg}_{2} \mathrm{Sn}_{0.75} \mathrm{Ge}_{0.25}$. Although the $Z T$ of $\mathrm{AgPb}_{\mathrm{m}+\mathrm{x}} \mathrm{SbTe}_{\mathrm{m}+2}\left(1.5\right.$ at $\left.425{ }^{\circ} \mathrm{C}\right)$ is larger than that of $\mathrm{Mg}_{2} \mathrm{Sn}_{0.75} \mathrm{Ge}_{0.25}\left(1.35\right.$ at $\left.425{ }^{\circ} \mathrm{C}\right)$, the (ZT) eng of $\mathrm{AgPb}_{\mathrm{m}} \mathrm{SbTe}_{\mathrm{m}+2}\left(0.53\right.$ at $\left.425{ }^{\circ} \mathrm{C}\right)$ is lower than that of $\mathrm{Mg}_{2} \mathrm{Sn}_{0.75} \mathrm{Ge}_{0.25}\left(0.64\right.$ at $\left.425^{\circ} \mathrm{C}\right)$, where $T_{c}=50^{\circ} \mathrm{C}$. The higher (ZT) eng corresponds to higher efficiency, as shown in Fig. 5(f). Fig. 6 (a-f) shows thermoelectric performance of the selected p-type materials, including Bio.4 $\mathrm{Sb}_{1.6} \mathrm{Te}_{3}$ [11], $\mathrm{MgAgSb}$ [57], $\mathrm{Lax}_{x} \mathrm{Ce}_{y} \mathrm{Fe}_{3.5} \mathrm{Co}_{0.5 \mathrm{Sb}}{ }_{12}$ [54], $\mathrm{PbTe} 0.15 \mathrm{Se} 0.85$ [58], $\mathrm{Cu}_{2} \mathrm{Se}$ [33], $\mathrm{Hf} 0.8 \mathrm{Zr} 0.2 \mathrm{CoSb}$ [20], and $\mathrm{Si}_{0.8} \mathrm{Ge}_{0.2} \mathrm{~B}_{0.05}$ [19]. Another most important feature, in Fig. 5 and Fig. 6, is the temperature dependent similarity between the $(Z T)_{\text {eng }}$ and efficiency, and also between $(P F)_{\text {eng }}$ and output power. As an example, for p-type BiSbTe, there is a peak in both conventional $Z T$ curve (Fig. 6(b)) and $P F$ curve (Fig. 6(a)), but not in the final efficiency (Fig. 6(f)) and output power (Fig. 6(e)). In contrast, the temperature dependent (ZT) eng $\&(P F)_{\text {eng }}$ cover more features of the temperature dependent efficiency and output power, respectively. It is suggested that the newly defined engineering thermoelectric parameters, i.e. $(Z T)_{\text {eng }} \&(P F)_{\text {eng, }}$, are much better to represent the efficiency and output power directly as compared with conventional $Z T \& P F$. Here, we consider $Z T \& P F$ as a local temperature point performance, while $(Z T)_{\text {eng }} \&(P F)_{\text {eng }}$ as a global temperature range performance from $T_{c}$ to $T_{h}$, where the boundary temperatures for $(Z T)_{\text {eng }} \&(P F)_{\text {eng }}$ are important. We also propose the forms for $(Z T)_{\text {eng }} \&(P F)_{\text {eng }}$ with boundary temperatures , i.e. $(Z T)_{T c}^{T h} \&(P F)_{T c}^{T h}$, respectively. As an example, for n-type MgSnGe, $(Z T)_{50^{\circ} \mathrm{C}}^{45{ }^{\circ} \mathrm{C}}=0.69$ while $(P F)_{50^{\circ} \mathrm{C}}^{45{ }^{\circ} \mathrm{C}}=2.09 \mathrm{~W} \mathrm{~m}^{-1} \mathrm{~K}^{-1}$. Fundamentally, both the local $Z T \& P F$ parameters and global $(Z T)_{\text {eng }} \&(P F)_{\text {eng }}$ parameters are important for thermoelectric research.

Additionally, it is noted in Fig 5(f) and Fig 6(f) that the maximum efficiency for most of the materials have reduction factor of $\sim 20 \%$, as compared with carrot efficiency (red dash line). By considering both the output power and efficiency, conventional $\mathrm{Bi}_{2} \mathrm{Te}_{3}$, filled Skutterudite, and half-Heusler alloys are the most promising materials for power generation applications. 
Some new materials such as p-type $\mathrm{MgAgSb}$ [57] and $\mathrm{NbFeSb}$ [59], n-type $\mathrm{Mg}_{2} \mathrm{Sn}_{0.75} \mathrm{Ge}_{0.25}$ [38] and $\mathrm{Mg}_{2} \mathrm{Sn}_{0.7} \mathrm{Si}_{0.3}[60]$ are worthy more attention in the near future.

In summary, the importance of power factor was addressed from a viewpoint of thermoelectric power generator by pointing out that lowering $\kappa$ leads to severe thermomechanical issues while tuning $P F$ does not influence thermo-mechanical stability. Thus, increasing $P F$ was suggested as an alternative strategy to boost the efficiency as well as output power generation as compared with the conventional route of lowering the lattice thermal conductivity. Finally, our recently developed $(Z T)_{\text {eng }} \&(P F)_{\text {eng }}$ are proposed as the better global indices to cover both the temperature dependent maximum efficiency \& output power, as compared with conventional $Z T \& P F$.

\section{Acknowledgement:}

This work is supported by "Solid State Solar-Thermal Energy Conversion Center ( $\left.{ }^{3} \mathrm{TEC}\right)$ ", an Energy Frontier Research Center funded by the U.S. Department of Energy, Office of Science, Office of Basic Energy Science under award number DE-SC0001299/DE-FG02-09ER46577.

\section{References:}

[1]. A. F. Ioffe, Semiconductor Thermoelements and Thermoelectric Cooling, Infosearch, London, 1957.

[2]. H. J. Goldsmid, A. R. Sheard, D. A. Wright, Br. J. Appl. Phys. 9 (1958) 365-370.

[3]. B. Abeles, D. S. Beers, G. D. Cody, J. P. Dismukes, Phys. Rev. 125 (1962) 44-46.

[4]. C. Wood, Rep. Prog. Phys. 51 (1988) 459-539.

[5]. B. C. Sales, D. Mandrus, R. K. Williams, Science 272 (1996) 1325-1328.

[6]. L. D. Hicks, M. S. Dresselhaus. Phys. Rev. B 47 (1993) 12727-12731.

[7]. R. Venkatasubramanian, E. Siivola, T. Colpitts, B. O’Quinn, Nature 413 (2001) 597-602.

[8]. M. S. Dresselhaus, G. Chen, M. Y. Tang, R. G. Yang, H. Lee, D. Z. Wang, Z. F. Ren, J. P. Fleurial, P. Gogna, Adv. Mater. 19 (2007) 1043-1053. 
[9]. K. F. Hsu, S. Loo, F. Guo, W. Chen, J. S. Dyck, C. Uher, T. Hogan, E. K. Polychroniadis, M. G. Kanatzidis, Science 303 (2004) 818-821.

[10]. W. Kim, J. Zide, A. Gossard, D. Klenov, S. Stemmer, A. Shakouri, A. Majumdar, Phys. Rev. Lett. 96 (2006) 045901-4.

[11]. B. Poudel, Q. Hao, Y. Ma, Y. C. Lan, A. Minnich, B. Yu, X. Yan, D. Z. Wang, A. Muto, D. Vashaee, X. Y. Chen, J. M. Liu, M. S. Dresselhaus, G. Chen, Z. F. Ren, Science 320 (2008) 634-638.

[12]. Y. C. Lan, B. Poudel, Y. Ma, D. Z. Wang, M. S. Dresselhaus, G. Chen, Z. F. Ren, Nano Lett. 9 (2009) 1419-1422.

[13]. X. B. Zhao, X. H. Ji, Y. H. Zhang, T. J. Zhu, J. P. Tu, X. B. Zhang, Appl. Phys. Lett. 86 (2005) 062111-3.

[14]. C. Nethravathi, C. R. Rajamathi, M. Rajamathi, R. Maki, T. Mori, D. Golberg, Y. Bando, J. Mater. Chem. A 2 (2014) 985-990.

[15]. P. F. P. Poudeu, J. D’Angelo, A. D. Downey, J. L. Short, T. P. Hogan, M. G. Kanatzidis, Angew. Chem. 118 (2006) 3919 -392.

[16]. W. S. Liu, B. P. Zhang, L. D. Zhao, J. F. Li, Chem. Mater. 20 (2008) 7526-7531.

[17]. W. J. Xie, J. He, H. J. Kang, X. F. Tang, S. Zhu, M. Laver, S. Y. Wang, J. R. D. Copley, C. M. Brown, Q. J. Zhang, T. M. Tritt. Nano Lett. 10 (2010) 3283-3289.

[18]. Z. Xiong, X. H. Chen, X. Y. Huang, S. Q. Bai, L. D. Chen, Acta Mater. 58 (2010) 39954002 .

[19]. G. Joshi, H. Lee, Y. C. Lan, X. W. Wang, G. H. Zhu, D. Z. Wang, R. W. Gould, D. C. Cuff, M. Y. Tang, M. S. Dresselhaus, G. Chen, Z. F. Ren, Nano Lett. 8 (2008) 4670-4674.

[20]. X. Yan, W. S. Liu, H. Wang, S. Chen, J. Shiomi, K. Esfarjani, H. Z. Wang, D. Z. Wang, G. Chen, Z. F. Ren, Energy Environ. Sci. 5 (2012) 7543-7548.

[21]. K. Biswas, J. Q. He, I. D. Blum, C. I. Wu, T. P. Hogan, D. N. Seidman, V. P. Dravid, M. G. Kanatzidis, Nature 489 (2012) 414-418.

[22]. Y. Z. Pei, J. Lensch-Falk, E. S. Toberer, D. L. Medlin, G. J. Snyder. Adv. Funct. Mater. 21 (2011) 241-249.

[23]. G. Rogl, D. Setman, E. Schafler, J. Horky, M. Kerber, M. Zehetbauer, M. Falmbigl, P. Rogl, E. Royanian, E. Bauer, Acta Mater. 60 (2012) 2146-2157. 
[24]. Q. Y. Zhang, H. Z. Wang, Q. Zhang, W. S. Liu, B. Yu, H. Wang, D. Z. Wang, G. Ni, G. Chen, Z. F. Ren, Nano Lett. 12 (2012) 2324-2330.

[25]. C. L. Wang, X. K. Gu, F. Dang, T. Itoh, Y. F. Wang, H. Sasaki, M. Kondo, K. Koga, K. Yabuki, G. J. Snyder, R. G. Yang, K. Koumoto, Nat. Mater. 14 (2015) 622-627.

[26]. H. Wang, J. F. Li, M. M. Zou, T. Sui, Appl. Phys. Lett. 93 (2008) 202106-3.

[27]. A. Charoenphakdee, K. Kurosaki, H. Muta, M. Uno, S. Yamanaka, Jpn. J. Appl. Phys. 48 (2009) 011603.

[28]. C. A. Cox, E. S. Toberer, A. A. Levchenko, S. R. Brown, G. J. Snyder, A. Navrotsky, S. M. Kauzlarich, Chem. Mater. 21 (2009) 1354-1360.

[29]. X. Y. Shi, F. Q. Huang, M. L. Liu, L. D. Chen, Appl. Phys. Lett. 94 (2009) 122103-3.

[30]. J. S. Rhyee, K. H. Lee, S. M. Lee, E. Cho, S. I. Kim, E. S. Lee, Y. S. Kwon, J. H. Shim, G. Kotliar, Nature 459 (2009) 965-968.

[31]. L. D. Zhao, D. Berardan, Y. L. Pei, C. Byl, L. Pinsard-Gaudart, N. Dragoe, Appl. Phys. Lett. 97 (2010) 092118-3.

[32]. F. Gascoin, A. Maignan, Chem. Mater. 23 (2011) 2510-2513.

[33]. B. Yu, W. S. Liu, S. Chen, H. Wang, H. Z. Wang, G. Chen, Z. F. Ren, Nano Energy 1 (2012) 472-478.

[34]. T. Plirdpring, K. Kurosaki, A. Kosuga, T. Day, S. Firdosy, V. Ravi, G. J. Snyder, A. Harnwunggmoung, T. Sugahara, Y. Ohishi, H. Muta, S. Yamaaka, Adv. Mater. 24 (2012) 3622-3626.

[35]. Q. Zhang, B. L. Liao, Y. C. Lan, K. Lukas, W. S. Liu, K. Esfarjani, C. P. Opeil, D. Broido, G. Chen, Z. F. Ren, Proc. National. Acad. Sci. USA 110 (2013) 13261-13266.

[36]. L. D. Zhao, S. H. Lo, Y. S. Zhang, H. Sun, G. J. Tan, C. Uher, C. Wolverton, V. P. Dravid, M. G. Kanatzidis, Nature 508 (2014) 373-377.

[37]. Y. F. Hu, J. Wang, A. Kawamura, K. Kovnir, S. M. Kauzlarich, Chem. Mater. 27 (2015) $343-351$.

[38]. W. S. Liu, H. S. Kim, S. Chen, Q. Jie, B. Lv, M. L. Yao, Z. S. Ren, C. P. Opeil, S. Wilson, C. W. Chu, Z. F. Ren, Proc. National. Acad. Sci. USA 112 (2015) 3269-3274.

[39]. W. S. Liu, K. C. Lukas, K. McEnaney, S. Y. Lee, Q. Zhang, C. P. Opeil, G. Chen, Z. F. Ren, Energy Environ. Sci. 6 (2013) 552-560. 
[40]. H. S. Kim, W. S. Liu, G. Chen, C. W. Chu, Z. F. Ren, Proc. National. Acad. Sci. USA 112 (2015) 8205-8210.

[41]. G. D. Mahan, J. Appl. Phys.70 (1991) 4551-4554.

[42]. R. He, H. S. Kim, Y. Lan, D. Z. Wang, S. Chen, Z. F. Ren, RSC Adv. 4 (2014) 6471164716.

[43]. Q. Y. Zhang, H. Wang, W. S. Liu, H. Z. Wang, B. Yu, Q. Zhang, Z. T. Tian, G. Ni, S. Y. Lee, K. Esfarjani, G. Chen, Z. F. Ren, Energy Environ. Sci. 5 (2012) 5246-5251.

[44]. S. Chen, K. C. Lukas, W. S. Liu, C. P. Opeil, G. Chen, Z. F. Ren, Adv. Energy Mater. 3 (2013) 1210-1214.

[45]. S.Y. Lee, K. Esfarjani, T. F. Luo, J. W. Zhou, Z. T. Tian, G. Chen, Nat. Comm. 5 (2014) 3525.

[46]. E. Suhir, J. Electron. Packag. 125 (2003) 261-267.

[47]. E. Suhir, A. Shakouri, J. Appl. Mech. 80 (2013) 021012-11.

[48]. Th. Clin, S. Turenne, D. Vasilevskiy, R. A. Masut, J. Electron. Mater. 38 (2009) 9941001.

[49]. H. Schock, G. Brereton, E. Case, J. D’Angelo, T. Hogan, M. Lyle, R. Maloney, K. Moran, J. Novak, C. Nelson, A. Panayi, T. Ruckle, J. Samamoto, T. Shih, E. Timm, L. Zhang, G. Zhu, J. Energy Resource Tech. 135 (2013) 022001-9.

[50]. W. S. Liu, Q. Jie, H. S. Kim, Z. F. Ren, Acta Mater. 87 (2015) 357-376.

[51]. W. S. Liu, H. Z. Wang, L. J. Wang, X. W. Wang, G. Joshi, G. Chen, Z. F. Ren, J. Mater. Chem. A 1 (2013) 13093-13100.

[52]. H. S. Kim, T. B. Wang, W. S. Liu, Z. F. Ren, 2015 (Submitted) Critical thermal conductivity.

[53]. M.T. Barako, W. Park, A. M. Marconnet, M. Asheghi, K. E. Goodson, J. Electron. Mater. 42 (2013) 372-380.

[54]. Unpublished data: $3^{\text {rd }}$ repressed $\mathrm{Bi}_{2} \mathrm{Te}_{2.7} \mathrm{Se}_{0.3} ; \mathrm{Ba}_{x} \mathrm{La}_{y} \mathrm{Yb}_{z} \mathrm{Co}_{4} \mathrm{Sb}_{12} ; \mathrm{La}_{x} \mathrm{Ce}_{y} \mathrm{Fe}_{3.5} \mathrm{Co}_{0.5} \mathrm{Sb}_{12}$.

[55]. M. Zhou, J. F. Li, T. Kita, J. Am. Chem. Soc. 130 (2008) 4527-4532.

[56]. X. W. Wang, H. Lee, Y. C. Lan, G. H. Zhu, G. Joshi, D. Z. Wang, J. Yang, A. J. Muto, M. Y. Tang, J. Klatsky, S. Song, M. S. Dresselhaus, G. Chen, Z. F. Ren, Appl. Phys. Lett. 93 (2008)193121-3. 
[57]. J. H. Sui, J. Shuai, Y. C. Lan, Y. Liu, R. He, D. Z. Wang, Q. Jie, Z. F. Ren, Acta Mater. 87 (2015) 266-272.

[58]. Q. Zhang, F. Cao, W. S. Liu, K. Lukas, B. Yu, S. Chen, C. P. Opeil, D. Broido, G. Chen, Z. F. Ren, J. Am. Chem. Soc. 134 (2012)10031-10038.

[59]. G. Joshi, R. He, M. Engber, G. Samsonidze, T. Pantha, E. Dahal, K. Dahal, J. Yang, C. Y. Lan, B. Kozinsky, Z. F. Ren, Energy Environ. Sci. 7 (2014) 4070-4076.

[60]. W. Liu, X. J. Tian, K. Yin, H. J. Liu, X. F. Tang, J. Shi, Q. J. Zhang, C. Uher, Phys. Rev. Lett. 108 (2012) 166601. 

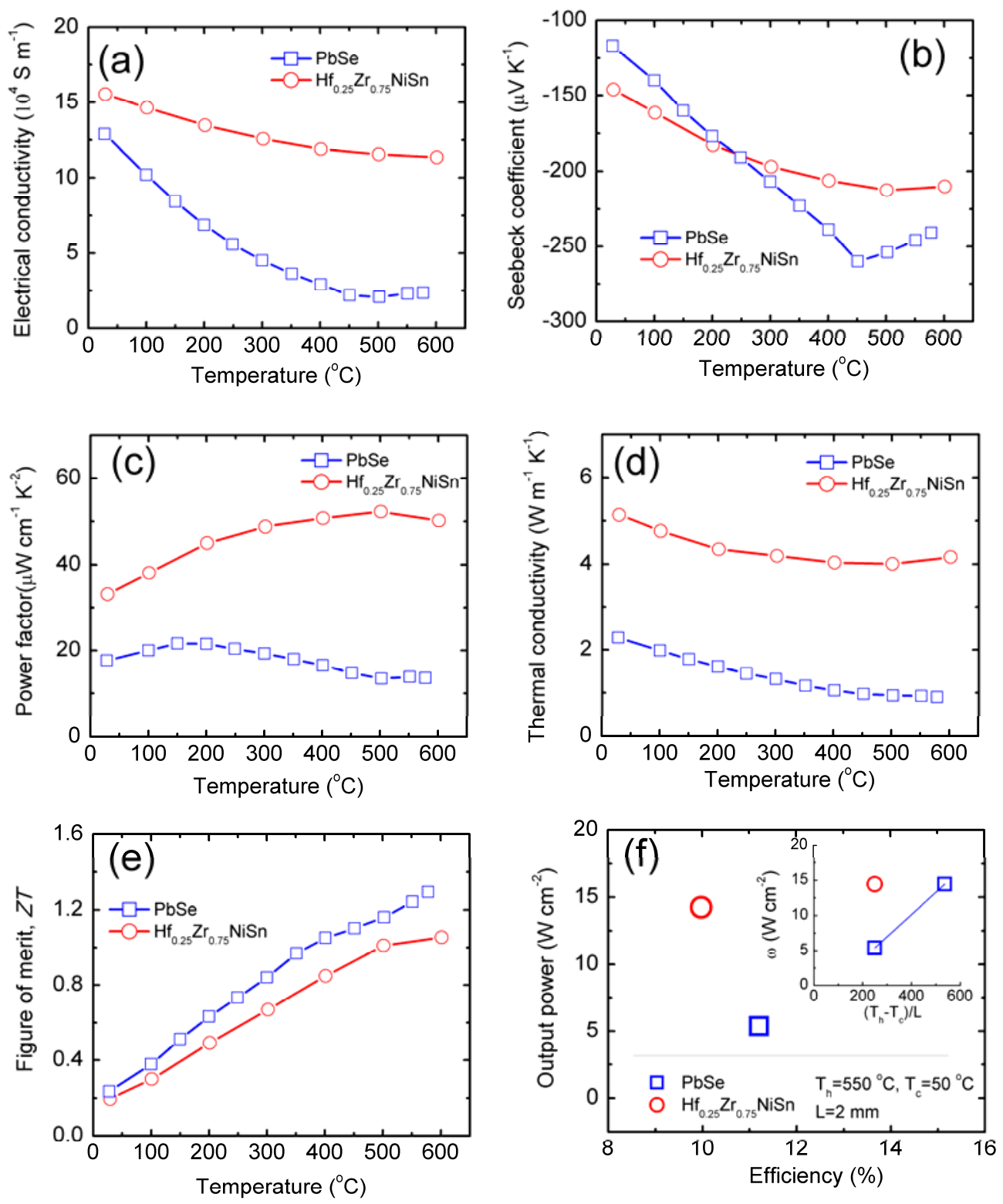

Fig. 1 Comparison of thermoelectric properties between two reported thermoelectric materials PbSe [43] and $\mathrm{Hf}_{0.25} \mathrm{Zr}_{0.75} \mathrm{NiSn}$ [44]: (a) electrical conductivity, (b) Seebeck coefficient, (c) power factor, (d) thermal conductivity, (e) figure of merit (ZT), (f) leg output power by numerical calculation. 


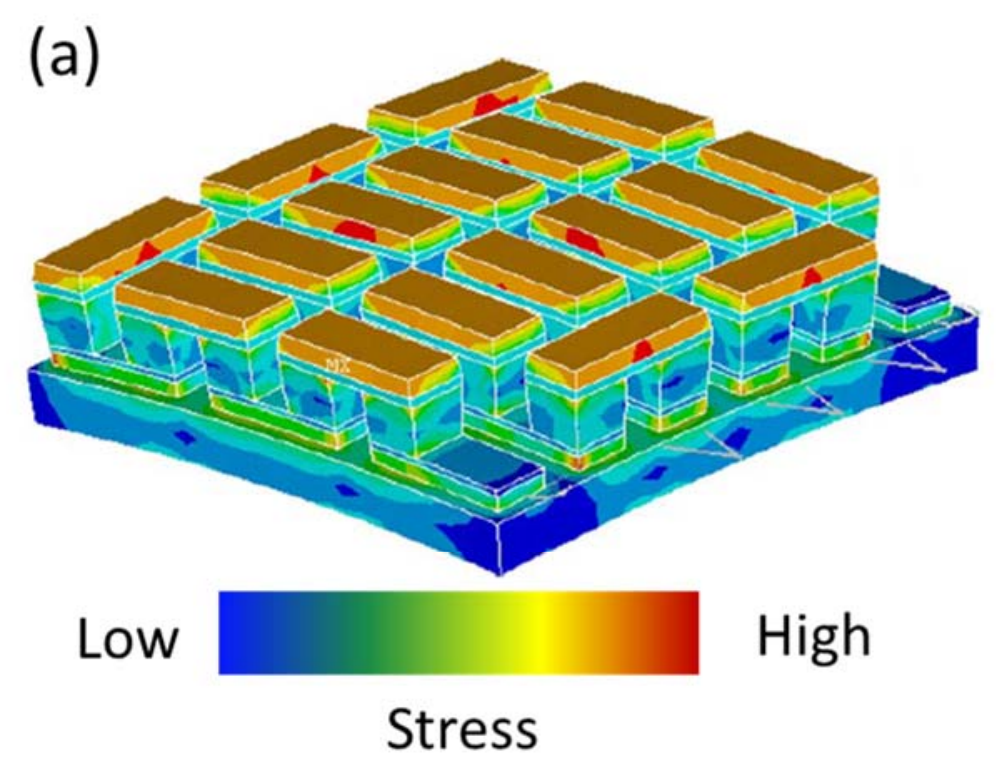

(b)

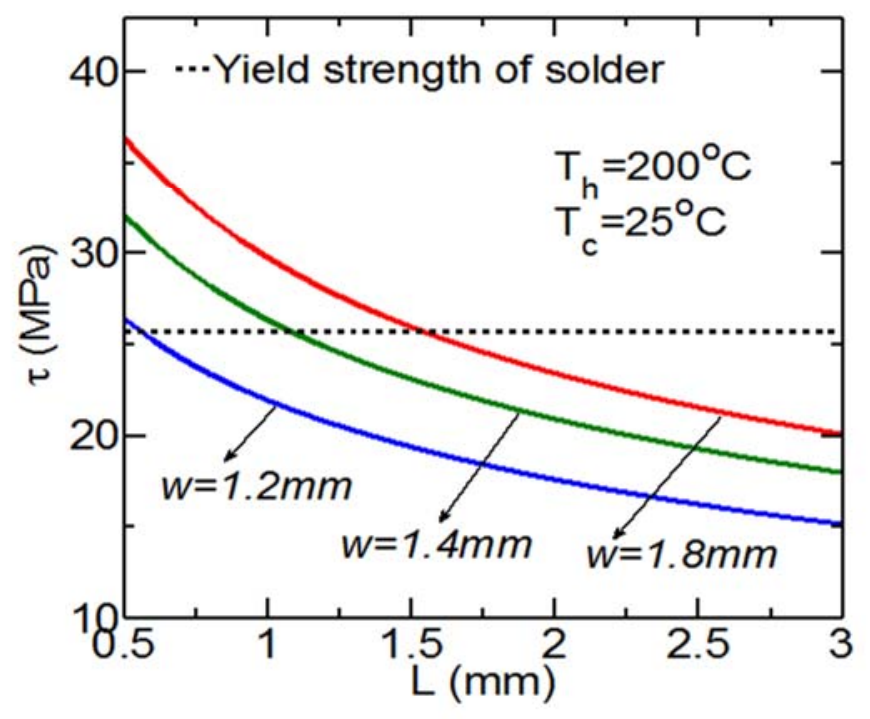

Fig. 2 (a) Stress distribution in a $\mathrm{Bi}_{2} \mathrm{Te}_{3}$ module subjected to a temperature difference of $100{ }^{\circ} \mathrm{C}$ while keeping unconstrained surface in $\mathrm{Bi}_{2} \mathrm{Te}_{3}$, simulated by ANSYS finite element method [48]. (b) Numerical calculation of the leg size dependent maximum shear stress at the interfacial between the $\mathrm{Cu}$ electrode and the $\mathrm{Bi}_{0.5} \mathrm{Sb}_{1.5} \mathrm{Te}_{3}$ leg [52]. 


\section{Before Thermal Cycling}

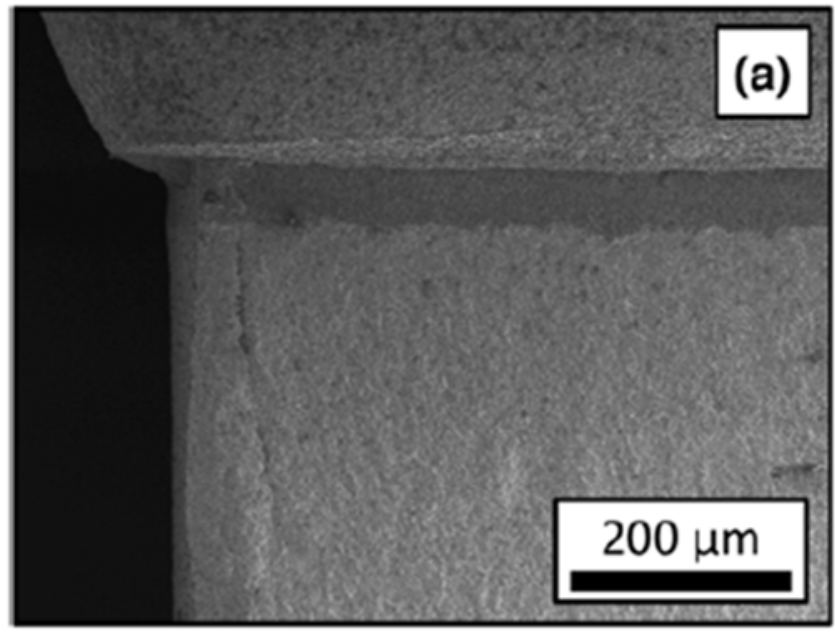

After Device Failure

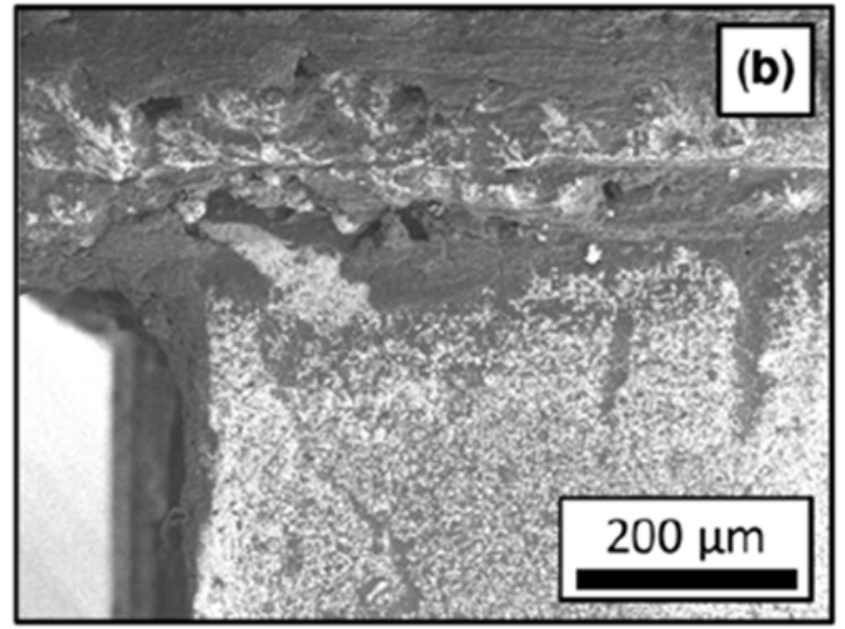

Fig. 3, Comparison of the interface between $\mathrm{Cu}$ electrode and the $\mathrm{Bi}_{2} \mathrm{Te}_{3}$ leg: (a) before thermal cycles and (b) after thermal cycles [53]. 


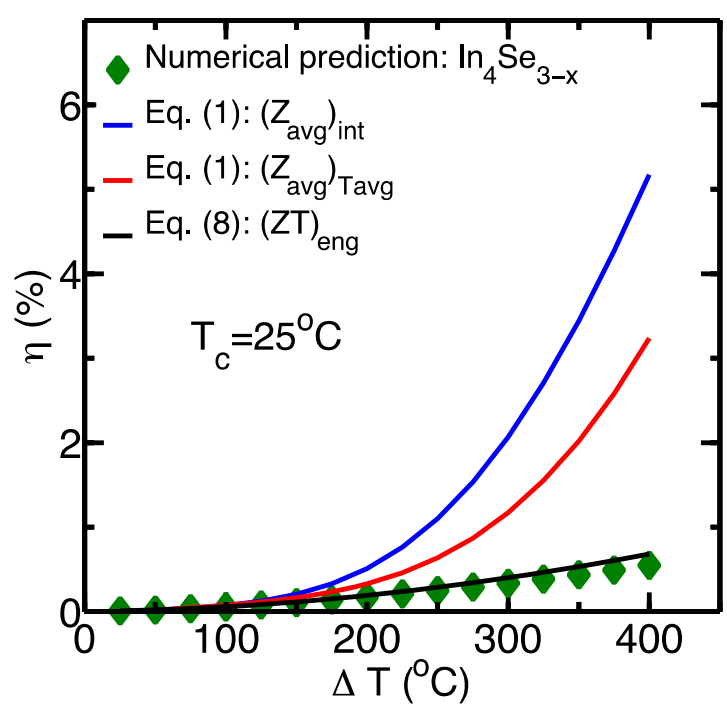

Fig. 4. Estimation of leg efficiencies for $\operatorname{In}_{4} \mathrm{Se}_{3-x}$ by using different models: numerical prediction of ideal (solid diamonds), by conventional formula using integration (blue line) and average temperature (red line) for $Z_{a v g}$, and by the new formula (black line) [40]. 

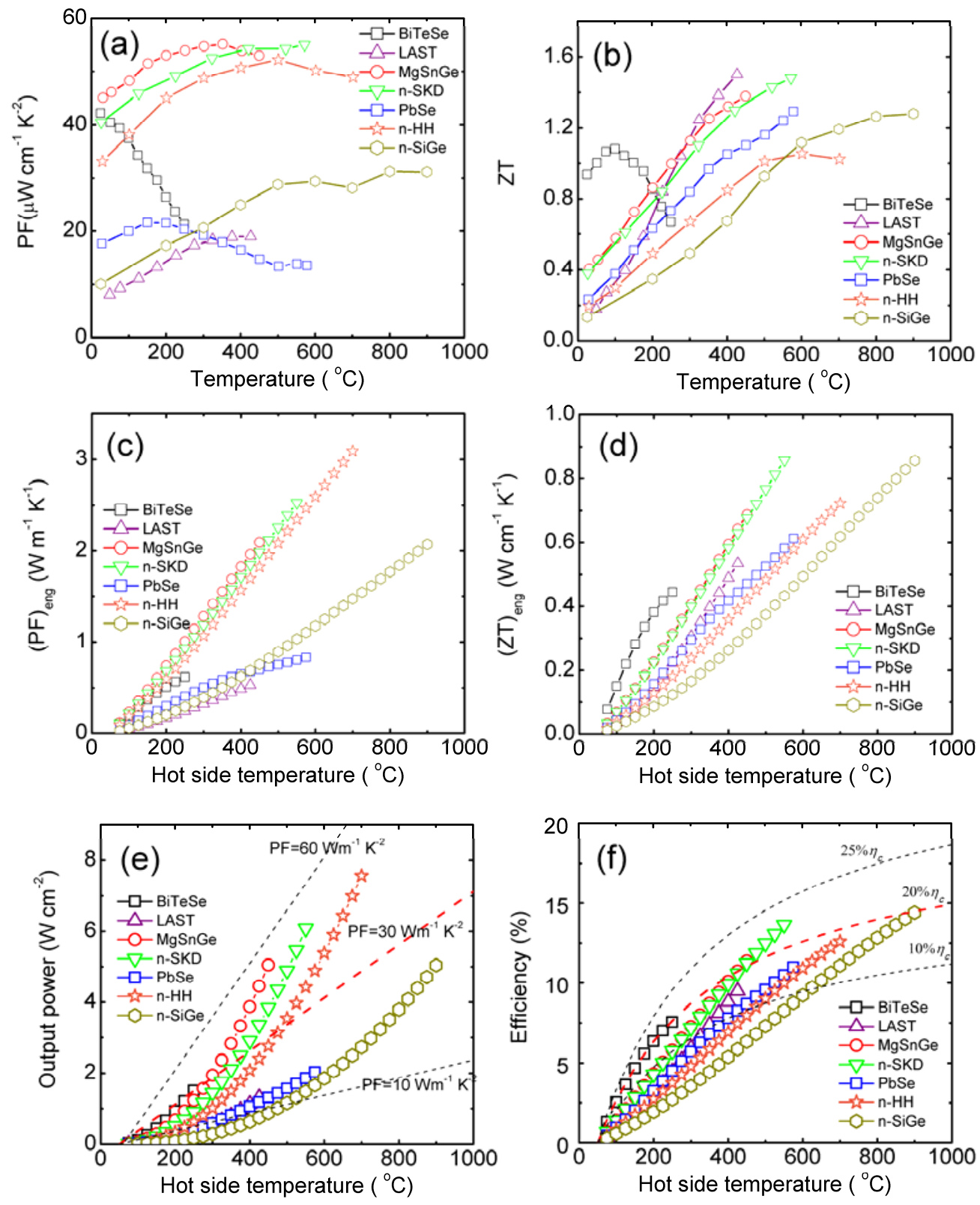

Fig. 5. Thermoelectric performance of selected n-type materials, (a) $P F$, (b) ZT, (c) $(P F)_{\text {eng, (d) }}$ (ZT) eng, (e) output powder, and (f) efficiency. BiTeSe: $3^{\text {rd }}$ repressed $\mathrm{Bi}_{2} \mathrm{Te}_{2.7} \mathrm{Se}_{0.3}$ [54], LAST: $\mathrm{AgPb}_{\mathrm{m} S b T e} \mathrm{~m}_{2}$ [55], MgSnGe: $\mathrm{Mg}_{2} \mathrm{Sn}_{0.75} \mathrm{Ge}_{0.25}$ [38], n-SKD: $\mathrm{Ba}_{x} \mathrm{Lay}_{y} \mathrm{Yb}_{z} \mathrm{Co}_{4} \mathrm{Sb}_{12}$ [54], PbSe [43], n-HH: Hf $0.25 \mathrm{Zr} 0.75 \mathrm{NiSn}$ [44] and n-SiGe: Sio.8Ge0.2P $\mathrm{P}_{0.02}$ [56]. The dash line in (e) is calculated by Eq. (2) by using a constant $P F$; the dash line in (f) is the partial Carrot efficiency, $\eta_{\mathrm{c}}=\left(\mathrm{T}_{\mathrm{h}}-\mathrm{T}_{\mathrm{c}}\right) / \mathrm{T}_{\mathrm{h}}$. $T_{c}=25^{\circ} \mathrm{C}$ for (c)-(f). 

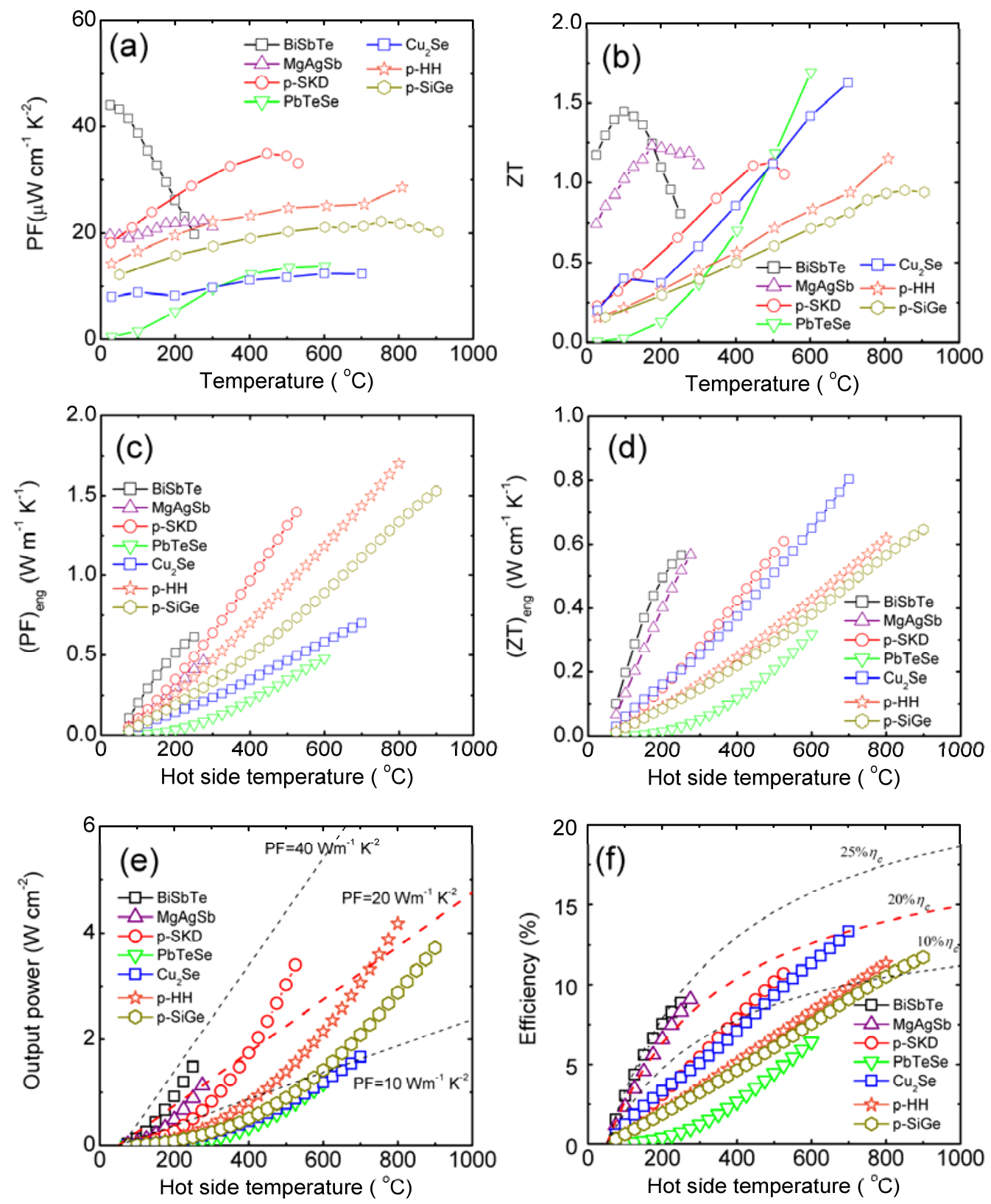

Fig. 6. Thermoelectric performance of selected p-type materials, (a) $P F$, (b) $Z T$, (c) $(P F)_{e n g}$, (d) $(Z T)_{e n g},(\mathrm{e})$ output powder, (f) efficiency. BiSbTe: Bi0.4Sb $\mathrm{Sb}_{1.6}$ [11], MgAgSb [57],

$\mathrm{La}_{\mathrm{x}} \mathrm{Ce}_{\mathrm{y}} \mathrm{Fe}_{3.5} \mathrm{Co}_{0.5} \mathrm{Sb}_{12}$ [54], $\mathrm{PbTe}_{0.15} \mathrm{Se}_{0.85}$ [58], $\mathrm{Cu}_{2} \mathrm{Se}$ [33], $\mathrm{Hf}_{0.8} \mathrm{Zr}_{0.2} \mathrm{CoSb}$ [20] and $\mathrm{Si}_{0.8} \mathrm{Ge}_{0.2} \mathrm{~B}_{0.05}$ [19]. The dash line in (e) is calculated by Eq. (2) by using a constant $P F$; the dash line in (f) is the partial Carrot efficiency, $\eta_{c}=\left(T_{h}-T_{c}\right) / T_{h} . T_{c}=50{ }^{\circ} \mathrm{C}$ for (c)-(f). 